\title{
THE IMPORTANCE OF EMPLOYEE MOTIVATION TO INCREASE ORGANIZATIONAL PERFORMANCE
}

\author{
Ioan Moise Achim ${ }^{l}$ \\ Larisa Dragolea ${ }^{2}$ \\ George Bălan ${ }^{3}$
}

\begin{abstract}
The present study starts from the premise of understanding the concept of "motivation" by everyone, and the importance of this phenomenon, in general. Despite the fact that it is permanently approached in specialty works, discussed and analyzed at congresses, seminars and internal meetings, motivation seems to continue to conceal secrets for (too) many employers, while the polls with the employees hired in big companies certainly demonstrate that they are not motivated in accordance with the contribution they bring to the company welfare.

Though the financial side of motivation is widely preferred and known by the both parts - employer and employee -, in the present study we shall insist and plead for the possibilities of application and the results of the efficient non-financial motivation plan to the internal climate and the lasting performance of the firm.

The aim of the present work is to understand the strategic importance of the non-financial motivation in the management process, being well known the fact that the performance obtained at the level of organization as well as its prestige crucially depend upon the quality of human resource motivation.
\end{abstract}

Keywords: motivation, human resource, job satisfaction.

JEL Codes: M54, J53.

\section{Introduction. Motivation, from art to practical reality}

Starting from Dwight D. Eisenhower's statement, "Motivation is the art of getting people to do what you want them to do because they want to do it", and analyzing it in depth, we reach the conclusion that motivation, the power to influence people and their actions is an art that advertises many qualities. Expanding on the above, we may say that not everyone can motivate, but anyone can be motivated in various forms and ways.

Knowing the possibilities and forms of reasoning which fit each employee, according to their wishes and interests, we can stimulate the desire to want more, therefore, the drive function will take place in the best conditions for both employee and company.

At one time, employees were considered just another input into the production of goods and services. What perhaps changed this way of thinking about employees was research, referred to as the Hawthorne Studies, conducted by Elton Mayo from 1924 to 1932 (Dickson, 1973). This study found employees are not motivated solely by money and employee behavior is linked to their attitudes (Dickson, 1973).

Motivation is the set of states of the individual's needs that require to be satisfied and therefore pushes, incites and causes the individual to perform a series of actions in order to satisfy them.

\footnotetext{
1 „1Decembrie 1918” University of Alba Iulia, Romania, e-mail: achimmoise@yahoo.com.

2 "1Decembrie 1918" University of Alba Iulia, Romania, e-mail: larisadragolea@yahoo.com.

3 Romanian-German University of Sibiu,e-mail: gbmuscel@yahoo.com.
} 
One can say that motivation represents the synergistic effect of an amount of stimuli on the behavior of employees in performing their job duties. Therefore, managers have the responsibility to agree upon and to correlate the economic performance of the organization with the capacity, opportunities and needs of the employees, which is reflected in the company's management culture.

First of all, the motivational system is ment to meet all the employees' needs. As soon as their satisfaction is fulfilled, the employees will tend to outline an independent relationship between their involuntary wish of performing the professional activity and their mood. Considering this, the company will gain a major benefit from its employees` perfomances.

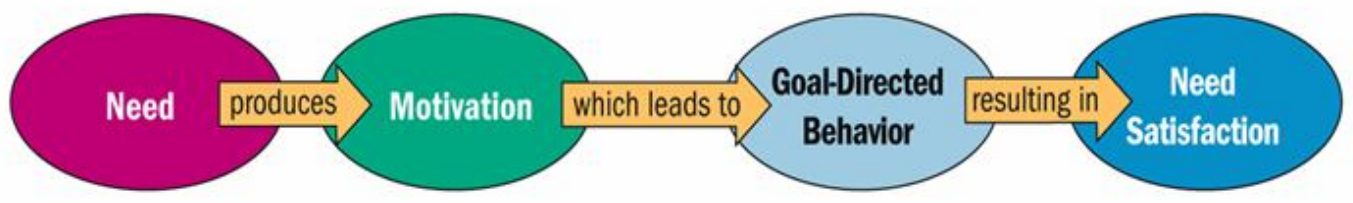

Figure no. 1 - Motivational System

Source: Author's individual contribution

A careful and accurate study of the phenomenon of motivation can guide you to finding some truthful answers to questions such as:

$\checkmark$ How can we stimulate employees to increase the company's profitability?

$\checkmark$ Which is the cause of the existence of different attitudes relating to forms of motivation?

$\checkmark$ What blocks a process of reasoning?

$\checkmark$ What is the importance of an incentives plan?

$\checkmark$ What are the measurable results/effects of a well designed and implemented reasoning plan?

$\checkmark$ Who are the right people to motivate?

$\checkmark$ What are the discouraging factors?

Specialized research emphasizes that, in any activity, poor human motivation leads to the use of only 20-30\% of the capacity of the individual, while a strong motivation recovers $80-90 \%$ of their potential (D.Cirnu).

We consider motivation as sine qua non factor in order to obtain long-term performance for the company. If the discouraging results are not that visible (they occur mainly in the form of informal discussions, remaining at this stage, between employees), the results of motivation are tangible results for the company, human resources being the most influential for achieving progress. Given the foregoing, we can contour the following relation of equivalence between motivating staff, company performance and employee satisfaction, motivation being, according to the authors of this work, in equivalence relation with the amount of business performance and staff satisfaction:

\begin{tabular}{|rrr|}
\hline Motivation of the staff & $<=>$ Performances & + Satisfaction \\
\hline For the company & For the employees \\
\hline
\end{tabular}

Figure no. 2. - Relation of equivalence between motivating staff, company performance and employee satisfaction

Source: Author's individual contribution

\section{Study on the current motivation of staff to SC Distribution S.R.L}

Each entity perceives motivation and the importance of this process differently. For this reason, we took into analysis a company with over 150 employees, well-renowned on the related market, which is the distribution of cooked products. 
This study was conducted in early 2013, the real name of the company not being made public for reasons of confidentiality, but renamed in our analysis S.C. Distribution SRL.

It is widely accepted that the company manager should ensure the achievement of the strategic objectives through the efforts of others. Creating an adequate climate for performance growth should be the concern of any manager who directly or indirectly engages in maximizing the results of his subordinates. This approach is influenced by three main factors: motivation, ability and resources. While resources may be allocated to the desired level and abilities may be formed by education and training, things are more difficult in terms of motivation.

Research methodology: objectives: making an analysis about the importance of motivation from the employee's perception, and how it reflects in his/hers work, whether consciously or not. The research is a descriptive one, because it shows our attempt to understand deeper the subjects' view upon the company`s motivational system and how can its influence be measured at an organizational level.

\section{The research instruments}

The method of research used was the psychological questionnaire method. In compiling the questionnaire, there were five major points, which we are goinf to briefly presented:

The subsistence evaluates the level of employees concern on basic needs (question 1, 12, $13)$;

The relationship factor evaluates the relationships quality between employees, regarding professional communication and collaboration. The low scores on this question show the existence of conflicts within the company, while the high scores state a warm collaboration climate between them. Questions: 9, 10, 11, 17, 20.

The motivation factor evaluates the motivational level in the company, assured by the remuneration system, personal development and promotions. The low scores on this question show the existence of a weak motivational system inside the organization, while the high scores mean a powerful motivational system. Questions: 2, 4, 5, 6, 8 .

The support factor evaluates the resources and the working conditions which the organizations is providing its employees with. The low scores show the lack of support, while the high scores mean a great support. Questions: 3, 7, 17 .

The expertise factor evaluates the willingness to perform the activities and how much employees want to stand out as professionists. Questions: 14, 15, 16, 19.

\section{Questioning the employees - working procedure}

For meaningful results, there had been compiled a questionnaire that included 20 questions

1. What was the employment reason at this company?

2. Do you think that there is a motivational and recognition system based on objectiv criteria?

3. Do you consider that your job fulfill all of your needs?

4. Do you get involved in finishing the tasks you were assigned?

5. Does the work you do motivate you?

6. What kind of reward stimulates you the best?

7. Do you believe that the company provides you job security?

8. Does your salary fairly reflect the tasks and responsibilities you have?

9. Is there communication between you and your colleagues?

10. Do you consider yourself sufficiently informed about the changes taking place inside the company?

11. Are the management decision taken in a transparent manner?

12. Do you have opportunities to earn a promotion at your current job? 
13. Do you have the necessary equipment/conditions to finish your duties efficiently?

14. Do you have opportunities to develop your skills?

15 . Do you know exactly what your duty is?

16. Is your work appreciated?

17. Is there a pleasant atmosphere inside the company?

18. Does your job emphasizes your qualities?

19. Are your work results visible?

20. Are your opinions listened to?

In order to validate the questionnaire, it was applied to 28 employees, from all hierarchy levels, with no time limit. From all the questionnaires, 3 of them were declared void, because they were not in correlation with the specific questions.

The subjects were informed about the purpose of the questionnaire, in order to obtain their approval on using the result in our study, in accordance with the psychological testing law. Also, the participants were assured of confidentiality and they were told that this research targets to improve their working conditions. This way, the ethical standards of research were respected.

Nevertheless, the participants were reminded that there were no good or bad answers, the only right answer was the one chosen by every each of them.

The research participants were asked to evaluate how much they agree or disagree with the questionnaire, by referring to the company they were working at.

The information was processed and submitted in the form of graphs.

\section{Result presentation:}

For the question related to the employment reason, we have the following answers: salary (28\%), career (24\%), experience (24\%), unemployed before (20\%), company atmosphere $(5 \%)$.

Regarding the motivational and recognition system, $60 \%$ of the employees are convinced that there is no such system in their company.

$24 \%$ of the staff consider that their working place meets all their needs, while $48 \%$ of them are unsatisfied. Only $16 \%$ of the employees consider that the company does not offer very good facilities.

As for the involvement in finishing the tasks, $76 \%$ of the subjects declare that they finish their tasks before deadlines and $20 \%$ of them say they get involved often. Yet, $4 \%$ say they occasionally perform their duties.

For the fifth question, the subjects`oppinions are different, but they tend towards neutrality. So, while $28 \%$ of them consider that they are always motivated by their work, $4 \%$ consider that their work does not stimulate them. $40 \%$ say that their job often stimulates them.

For the sixth question regarding the best rewards that motivates them, most of the employees (72\%) consider that money is the best one. Promotion stimulates only $20 \%$ of them, and $8 \%$ are stimulated by moral rewards only if they are being accompanied by money.

The job security system exists for only $48 \%$ of the subjects, while $8 \%$ of them say that it does not exist. Regarding the question about whether or not the salary fairly reflects the tasks and responsibilities they have, most of the respondents are not satisfied. (60\% - not satisfied, 32\% - not always satisfied, $28 \%$ - not really satisfied, $24 \%$ - satisfied by the salary)

For the nineth question, $60 \%$ of the employees say that they have always gone along well with their collaegues, $32 \%$ - most of the time and $8 \%$ say they communicate pretty rare with others. The employees are a solidary group in this company, communication is being really important.

The employees information level regarding the changes taking place within the company and which could affect them is considered unsatisfaing. $4 \%$ of the subjects consider that they are not informed, $20 \%$ - they are not very well informed, 52 - wish to be more informed and $24 \%$ consider they are properly informed. 
The management decisions are not an interest for $20 \%$ of the staff, $4 \%$ do not know what transparence means, $24 \%$ of the interviewed employees are questioning the company`s transparence and $52 \%$ consider that the decisions are visible enough for everyone.

$60 \%$ declared that there are high promotion chances, while $40 \%$ are questioning the possibilities.

The working equipment is not missing, yet $12 \%$ of the employees think they do not have all the necessary conditions. $72 \%$ of the respondents affirm that they have the chance to learn new things and $28 \%$ say they do not have this chance anymore.

A percentage of $100 \%$ of the staff confirms that everyone knows what his/hers tasks are. Only $56 \%$ of the employees feel like their work is being appreciated and $44 \%$ do not believe that their effort is farily evaluated.

Regarding the company`s atmosphere, $48 \%$ declare that it is a pleasant atmosphere, while $52 \%$ disagree. $60 \%$ of the subjects say that their job does no emphasizes their qualities and potential, and $40 \%$ say it does.

Regarding whether or not their results are visible, $96 \%$ say that they are, while $4 \%$ consider them unimportant.

Finally, $64 \%$ of the respondents think that their oppinions matter and are being listened to by their superiors while $34 \%$ of them disagree.

\section{Conclusions and suggestions for employees` motivation}

The subjects` best motivation is the financial gain, especially during the economical crisis Romania is going through. The career and experience gain are situated on two equal levels.

Most of the company`s employees feel like there is no motivational and recognition system, fact which is most probably reflected by the cultural management principles.

Most of the staff say they are unsatisfied by their working place. This answer was to be expected, considering the answers at the first question. The employees are getting involved in their daily activities, yet only a small number of them consider work as a motivational factor. This element is going to be reflected in a negative way in the company`s future preformances.

The rewards are a motivational factor for the questioned subjects, and most of them consider that they have a stable job.

Generally, at the analysed organization, the rewards equal the staff 's implication level and results. This fact is being emphasized and confirmed by the respondents.

The collaboration between employees is a good one, but the staff would like to be more informed about the changes within the organization.

The majority of the respondents consider that the company is being managed in a transparent manner and the promotion opportunities are many.

The employees are satisfied by the equipment/conditions and the fact that they can gain new knowledge is motivating them.

All the employees know their duties and responsibilities, but only half of them consider that their work is being appreciated. This should be an attention alarm for the company.

The results and the efforts are visible, the staff's oppinions are being listened to and taken into account.

Overall, the results of this study confirm the fact that the financial factor prevails, but the subordinates feel valued and appreciate the company`s management efforts and the policy of „open doors".

A recent study made by the TMI (Training \& Consulting) agency on the HR managers from Romania, shows that $62 \%$ and respectively $43 \%$ of them turn their efforts towards social development and teamwork. And because it is difficult to find valuable people, you must do everything to keep them. 
After reviewing the theories and finishing the research about the employees motivation, we suggest that the best ways to motivate employees at SC Distribution S.R.L are the following:

The financial stimulation made a direct link between rewards and productivity, with the role to boost performance growth. We propose that, at the subject company, there should be wages additions and group motivation.

As a form of independent simulation, we suggest that company`s employees should receive in addition to the direct agreement, a comission which is obtained on condition that they fulfill a minimum of accomplishments. Achievements which exceed the minimum percentage established by the company`s management should be awarded with bonuses. We also propose to grant awards to employees, also as an incentive for independent activities and results.

If independent motivation creates envy, group stimulation promotes cooperation and joint effort to obtain the best results. For the group motivation to be effective we suggest that:

$\checkmark$ group should not be too large, so that the employee would feel easily the effect his work has on the global result;

$\checkmark$ there should exist a real independence between individuals in the group, that can convince them of the importance of cooperation;

At the company's level, the motivation system includes all its employees in relation with the financial results obtained by the organization. We suggest that the main stimulation methods for all the staff shoud be:

$\checkmark$ knowing the incomes that the unit must achieve during a certain period of time, when there are considerable extra gains, the employees can be rewarded with a payment bonus monthly, quarterly or half-yearly;

$\checkmark$ profit sharing at the end of the year is best known and anticipated form of employees motivation, which we propose due to the size and timing of assessment of incentive payment (winter holidays). From the net profit obtained by the company, a share is intended to stimulate the entire staff at the end of the year ("the 13th salary");

$\checkmark \quad$ the possibility of purchasing the company`s shares is an investment which can bring advantages for both parties: the employer increases the capital, while the employee can obtain dividends at the end of the year.

Becoming a shareholder in the company you work for makes the employee more interested in outcomes that may increase engagement, loyalty and individual performance;

The objective appreciation of the performances achieved by every worker and establishing the rewards which are given as a prize for his/hers work, are also a motivational method which proves to be as effective as the financial stimulation.

By ensuring employees` participation in taking important decisions concerning the firm`s activity, through continuous consultation, is considered to be a form of recognition and appreciation of the staff s professional capacity.

The "quality circles", are some regular meetings of small working groups, which aim to identify the best ways to improve the quality of their work and results. The activity performed within the quality circles motivates the employees by involving them in finding solutions for problems which demand creativity and initiative.

There should be implemented flexible working methods, different from the usual ones, which allow workers to perform their assigned duties in periods of time that do not mix with personal issues. You can apply different variants of flexible programs:

$\checkmark$ various programs in which employees set periods of attendance at work, on condition that all the assigned tasks can be fulfilled during this time;

$\checkmark$ shared working schedule, in which a complex task is divided for one or more workers and everytime, its whole achievement returns to one worker;

$\checkmark$ shared working schedule, in which a complex task is divided for one or more different workers which must coordinate their efforts to fulfill the task before the deadlines; 


\section{Conclusions}

„If employees feel good in my company, they will surely take care of my customers". This ought to be one of the principles a manager must build his/hers motivational system.

Yerkes-Dodson`s law should not be forgotten: the performance grows through increasing the motivation, but only to a limit. Exceeding that limit can lead to a decrease of efficency (the balance between production and production capacity will be perturbed).

The proper employees` motivation is considered to be a philosophical management problem, regarding the relationships with the subordinates.

We must take into account that there can be a better HR management through an efficent motivation and recognition system. There should be a standard to evaluate the performances and how to allocate of the rewards. The promotion opportunities should be more open by increasing employees' skills through courses. The company ought to encourage the personal skills development and potential, to stimulate employees who fulfill their tasks perfectly. In case of new employees, the organization must show support for them and invest in creativity and initiative. Also, there must be a better performance dissemination.

\section{References}

1. Dickson W. J., 1973. Hawthorne experiments, In C. Heyel (ed.), The encyclopedia of management, 2nd ed. (pp. 298-302). New York: Van Nostrand Reinhold.

2. Gerhart B. \& Rynes S. L., 2003. Compensation: Theory, evidence, and strategic implications,. Thousand Oaks, CA: Sage

3. Herzberg F., Mausner B., Snyderman B. B., 1959. The motivation to work. New York: John Wiley \& Sons.

Lindner James R., 1998. Understanding Employee Motivation, Journal of Extension, , Vol.36, No:3

4. Kovach K. A., 1987. What motivates employees? Workers and supervisors give different answers. Business Horizons, 30. 58-65.

5. Maslow A. H., 1943. 1943. A theory of human motivation. Psychological Review, July. 1943, p. 370-396.

6. Simionescu A., Bud N., Buşe F., Stamin P. I., 2006. Managerial Control, Editura Economică. 